Original article

\title{
The study of Prosopic index of 17-26 year old normal population in Eastern Nepal: Ethnic and gender variation
}

\author{
Sandip Shah ${ }^{1}$, Laxman Khanal ${ }^{1}$, Sarun Koirala ${ }^{1}$, Soumya Chakraborty Bhattacharya ${ }^{2}$ \\ ${ }^{1}$ BP Koirala Institute of Health Sciences, Dharan, Nepal \\ ${ }^{2}$ West Bengal University of Health Sciences, Salt Lake City, Kolkata, West Bengal, India
}

Received 17 February 2015, Accepted 19 March 2015

(C) 2015, Shah S., Khanal L., Koirala S., Bhattacharya S.C.

(C) 2015, Russian Open Medical Journal

Abstract: Modern man is inclined to making comparison of various body parts in living or in cadaver for research and knowledge purpose. Political scientists, Joshi and Rose, broadly classify the Nepalese population into three major ethnic groups in terms of their origin: IndoNepalese (IND), Tibeto-Nepalese (TN) and Indigenous (IN). This study will provide a data base of facial measurements that will help maxillofacial surgeons with wide range of facial dimensions which would be helpful in facial reconstruction surgery.

The main objectives of this study were to find effect of ethnicity on prosopic index and to compare among both sexes of all ethnic races. The experimental protocol for the cross sectional study was approved by Institutional Ethical Review Board. This study was conducted in normal healthy pure ethnic racial population of sample size of 600 (300 male and 300 female) belonging to17-26 age group in Sunsari and Morang districts of Eastern Nepal. The data was collected among each ethnic race, i.e. Indgenous, Indo-Nepalese and Tibeto-Nepalese each consisting of 200 individuals (100 males and 100 females). Random sampling technique was done for data collection for the respective ethnic races during community visits. The participants were initially oriented to the purpose of the study and assured that anonymity would be maintained.

The results showed highly significant difference in face length (FL), face width (FW) and prosopic index (PI) among both sexes of all 3 ethnic races $(p<0.001)$. The mean $\mathrm{PI}$ of people of Eastern Nepal was 88.80 ; for males 88.47 and for females 89.12 respectively categorised as Mesoprosopic. The PI among Tibeto-Nepalese, Indigenous and Indo-Nepalese were 86.91 \pm 0.93 (Mesoprosopic), 88.40 \pm 1.18 (Mesoprosopic) and 91.09 \pm 0.69 (Leptoprosopic) respectively. Indo-Nepalese presents with long face (Leptoprosopic) while Indigenous and Tibeto-Nepalese have and round face (Mesoprosopic).

Keywords: reconstruction, ethnicity, prosopic index

Cite as Shah S, Khanal L, Koirala S, Bhattacharya SC. The study of Prosopic index of 17-26 year old normal population in Eastern Nepal: Ethnic and gender variation. Russian Open Medical Journal 2015; 4: e0201.

Correspondence to Dr Sandip Shah. E-mail: San230dip@yahoo.com

\section{Introduction}

Bodily measurements are the mainstay of anthropological research; however racial and sometimes ethnic variations exist between these measurements because human body dimensions are affected by ecological, biological, geographical, racial, gender, age related and nutritional factors [1]. Modern man is inclined to making comparison of various body parts in living or in cadaver for research and knowledge purpose [2]. Craniofacial anthropometry is a technique used in physical anthropometry comprising of precise and systematic measurement of the bones of the human skull with wide applications in forensic medicine, plastic surgery, orthodontics, archeology and identification of determining the origins of races [3].

Political scientists, Joshi and Rose in 1991, broadly classify the Nepalese population into three major ethnic groups in terms of their origin: Indo-Nepalese (IND), Tibeto-Nepalese (TN) and Indigenous (IN). In case of first two groups, the direction of their migration and Nepal's landscapes appeared to have led to their vertical distribution. Most ethnic groups are found at particular altitudes.The first group, comprising those of Indo-Nepalese origin, inhabit the more fertile lower hills, river valleys and Terai plains adjoining boundary of India. The second major group consist of communities of Tibeto-Nepalese origin occupying the higher hills from west to east. The third and much smaller group comprises of a number of tribal communities, such as the Tharus and the Dhimals of the Terai who may represent the Indo-Nepalese and Tibeto-Nepalese characteristics [4].

Therefore, the anthropometric studies play a significant role in distinguishing pure ethnic races versus the global mingling of races. No such study related to the facial anthropometry has been carried out in Eastern Nepal among Tibeto-Nepalese, IndoNepalese and Indigenous ethnic groups to the best of our knowledge. In view of differences observed in other studies, based on racial and ethnic differences, this study was designed to determine the types of face present in adult males and females of Eastern Nepal. This study will provide a data base of facial measurements that will help maxillo-facial surgeons with wide 
range of facial dimensions which would be helpful in facial reconstruction surgery.

The main objectives of this study was to find effect of ethnicity on prosopic index $(\mathrm{PI})$ measurements and to compare among both sexes of all ethnic races.

\section{Material and Methods}

The non-interventional comparative cross-sectional study was conducted in Department of Human Anatomy at B.P Koirala Institute of Health Sciences (BPKIHS) following Institutional Ethical and Research Board's permission. This study was conducted in normal healthy pure ethnic racial population of sample size of 600 (300 males and 300 females) belonging to 17-26 age group in Sunsari and Morang districts of Eastern Nepal. The data was collected among each ethnic race ie, Indgenous, Indo-Nepalese and Tibeto-Nepalese each consisting of 200 individuals (100 male and 100 female) in collaboration with Department of Community Medicine and School of Public Health and Department of Community Dentistry, BPKIHS.

Random sampling technique was done for data collection for the respective ethnic races during community visits. Good rapport building was done with participants, then informed consent was taken following which questionnaire was filled up which consists of general information along with facial measurements. The participants were initially oriented to the purpose of the study and assured that anonymity would be maintained. The subjects with craniofacial injury or deformity,chronic/systemic diseases, having family history of intercaste marriage and who did not wish to take part in the study were excluded.

\section{Anthropometric measurements and data analysis}

The participants were asked to sit on a chair in relaxed condition with their heads in anatomical position and the measurements were taken using a sliding caliper (straight and curve), manufactured by Syber Hegne and Company AG, technical product division, Wiesenstrausses $8, \mathrm{CH}-8008$ Zurich, Switzerland with standard anatomical landmarks. All the measurements were carried out after careful palpation of the face for anatomical landmarks and measurements were taken to the nearest $1 \mathrm{~mm}$ (Mibodi and Farahani, 2008). The Parameters measured were face length (FL) and face width (FW) in $\mathrm{mm}$.

Data obtained from each participants were recorded in a special form and data were transferred to a computer in MS Excel software. The data collected was tabulated and analysed using Statistical Package Social Sciences (SPSS) 11.5 version soft ware. Oneway Anova and independent t-test were used to compare the mean among different groups. $\mathrm{P}$ value $(0.05)$ was considered to see the significance differences.

\section{Operational definitions [5]}

Face length (FL) - It is the distance between nasion( $\mathrm{n}$ ) to the gnathion(gn).

a) Nasion ( $n$ ) - Most anterior point midway between the frontal and nasal bones on the fronto-nasal suture.

b) Gnathion (gn) - It is the most antero-inferior point on the symphysis of the chin.

Face width (FW) - It is the distance between the Zygomatic
Prosopic Index (PI) - It is the ratio of face length to face width multiplied by 100 :

$$
P I=(F L / F W) \times 100 \text {. }
$$

Depending upon indices the types of face shapes based on $\mathrm{PI}(\%)$ were classified as given below [6]:

a) Hypereuriprosopic (very broad face), <79.9;

b) Euriprosopic (broad face), 80.0- 84.9;

c) Mesoprosopic (round face), 85.0-89.9;

d) Leptoprosopic (long face), 90.0- 94.9;

e) Hyperleptoprosopic(very long face), $>95.0$.

\section{Results (Tables 1-5)}

The mean age of all participants was 20.21 years which included males as 20.81 years and females as 19.61 years.

In this study, the results showed highly significant difference in $\mathrm{FL}$,FW and PI among both sexes of all 3 ethnic races $(p<0.001)$. The mean PI of people of Eastern Nepal was 88.80; for males 88.47 and for females - 89.12 respectively, categorised as Mesoprosopic. The PI among Tibeto-Nepalese, Indigenous and Indo-Nepalese were 86.91 \pm 0.93 (Mesoprosopic), 88.40 \pm 1.18 (Mesoprosopic) and 91.09 \pm 0.69 (Leptoprosopic) respectively.

Table 1. Parameters for total sample of all ethnic races

\begin{tabular}{lc}
\hline \multicolumn{1}{c}{ Parameters } & Mean $\pm \mathrm{SD}$ \\
\hline $\mathrm{FL}, \mathrm{mm}$ & $119.57 \pm 4.54$ \\
$\mathrm{FW}, \mathrm{mm}$ & $134.62 \pm 2.97$ \\
$\mathrm{PI}, \%$ & $88.80 \pm 1.98$ \\
\hline
\end{tabular}

Table 2. Mean and standard deviation (SD) of parameters compared between males and females

\begin{tabular}{lccc}
\hline \multicolumn{1}{c}{ Parameters } & Male & Female & P-value \\
\hline $\mathrm{FL}, \mathrm{mm}$ & $119.57 \pm 4.55$ & $119.58 \pm 4.54$ & 0.979 \\
$\mathrm{FW}, \mathrm{mm}$ & $135.11 \pm 2.54$ & $134.14 \pm 3.28$ & $<0.001$ \\
$\mathrm{PI}, \%$ & $88.47 \pm 2.18$ & $89.12 \pm 1.69$ & $<0.001$ \\
\hline
\end{tabular}

Data presented as Mean \pm SD.

Table 3. All parameters among all ethnic groups

\begin{tabular}{lcccc}
\hline Parameters & TN group & IN group & IND group & P-value \\
\hline $\mathrm{FL}, \mathrm{mm}$ & $115.32 \pm 2.13$ & $118.27 \pm 2.23$ & $125.13 \pm 1.38$ & $<0.001$ \\
$\mathrm{FW}, \mathrm{mm}$ & $132.70 \pm 2.48$ & $133.81 \pm 2.58$ & $137.37 \pm 1.35$ & $<0.001$ \\
$\mathrm{PI}, \%$ & $86.91 \pm 0.93$ & $88.40 \pm 1.18$ & $91.09 \pm 0.69$ & $<0.001$ \\
\hline
\end{tabular}

Data presented as Mean \pm SD

Table 4. All parameters among males of all ethnic groups

\begin{tabular}{lcccc}
\hline Parameters & TN group & IN group & IND group & P-value \\
\hline $\mathrm{FL}, \mathrm{mm}$ & $115.41 \pm 2.17$ & $118.10 \pm 2.12$ & $125.19 \pm 1.354$ & $<0.001$ \\
$\mathrm{FW}, \mathrm{mm}$ & $133.68 \pm 2.38$ & $134.45 \pm 2.02$ & $137.21 \pm 1.66$ & $<0.001$ \\
$\mathrm{PI}, \%$ & $86.33 \pm 0.73$ & $87.84 \pm 0.80$ & $91.24 \pm 0.59$ & $<0.001$ \\
\hline
\end{tabular}

Data presented as Mean \pm SD.

Table 5. All parameters among females of all ethnic groups

\begin{tabular}{lcccc}
\hline Parameters & TN group & IN group & IND group & P-value \\
\hline $\mathrm{FL}, \mathrm{mm}$ & $115.23 \pm 2.10$ & $118.44 \pm 2.32$ & $125.06 \pm 1.32$ & $<0.001$ \\
$\mathrm{FW}, \mathrm{mm}$ & $131.72 \pm 2.17$ & $133.16 \pm 2.90$ & $137.53 \pm 0.92$ & $<0.001$ \\
$\mathrm{PI}, \%$ & $87.48 \pm 0.74$ & $88.96 \pm 1.23$ & $90.93 \pm 0.75$ & $<0.001$
\end{tabular}

Data presented as Mean \pm SD. arches. 


\section{Discussion}

Zhuang and Bradtmiller in Chinese population reported that FL in Males is slightly shorter in comparison to American subjects $(P<0.05)$ [7]. Lili $D$. et al. found significant differences in $F W$ of Chinese males and females which were larger than American Males and Females [8]. The present study showed that IndoNepalese population had longer FL and FW followed by Indigenous and Tibeto-Nepalese and PI was also found to be highest in IndoNepalese (89.12) followed by Indigenous (88.47) and TibetoNepalese (88.80) population. This study also showed that IndoNepalese males and females had longer FL, FW and PI followed by Indigenous and Tibeto-Nepalese. Therefore, Tibeto-Nepalese and Indigenous males and females were classified as Mesoprosopic whereas Indo-Nepalese as Leptoprosopic individuals.

In the study conducted in Northern Iran by Jahanshahi et al. (2008), PI for Fars Gorgani and Turkman baby boys were $71.19 \pm 10.89$ and $78.15 \pm 10.78$ respectively, which makes them hypereuriprosopic but their adult faces were found to be Mesoprosopic in both Fars and Turkman [5]. In this study, both males and females were found to be Mesoprosopic results being similar as seen for male Fars and Turkmans who were found to be mesoprosopic too. Regarding facial shapes based on the Prosopic indices (PI), obtained in this study, the general adult Eastern Nepal population were classified as Mesoprosopic in both sexes which differed significantly from work on neonates where the dominant facial form was found to be hypereuryprosopic type as conducted by Garba et al [9]. The results of this study, are in agreement with study results from other regions of the world where the Mesoprosopic and Hypereuryprosopic types were found to be the dominant type in Turkman newborns and native Fars newborns respectively as conducted by Golalipour et al. [10].

In Noori Mugahi et al's study, the mean and SD of PI was $86.79 \% \pm 5.87 \%$ and $86.53 \% \pm 6.76 \%$ for Sistani and Baluchi subjects respectively, the results being lower than that found in our study. In the Baluchi group, the dominant face type was found to be euryprosopic [11]. In Heidari et al's study, the PI was significantly different in Sistani (Fars) and Baluchi women, and the dominant face type in Sistani (Fars) and Baluchi women were euryprosopic, with a statistically significant difference between them. The rare types were hypereuryprosopic and hyperleptoprosopic in the Sistani and hyperleptoprosopic in the Baluchi groups. These findings also differed from our research findings [12].

However, our findings were similar to Farahani and Emami's study in Iran [13]. They reported that the dominant type of face shape of males and females aged 19-20 years was mesoprosopic. However the present study results did not agree with Mehrannia's study in Kermanshah, Iran which showed that face shapes in adult males (aged 16-55 years) were Euriprosopic [14]. Ghosh and Malik's study on the Indian population reported that the hypereuryprosopic and euryprosopic types of facial forms are present in the highest and equivalent percentages in Santhals. However, females are generally hypereuryprosopic, while males are euryprosopic in their total facial index. It reflects that Santhal females have a relatively broader face than their male counterparts [15]. According to the results of the study, people in Eastern Nepal are found to have a round face, compared to other population.

\section{Conclusion}

It can thus be concluded that Indo-Nepalese presents with long face (Leptoprosopic) while Indigenous and Tibeto-Nepalese have round face (Mesoprosopic). The study on the face shapes in this part of Nepal indicates that ethnicity and gender affect the form of any individual's face.

\section{Acknowledgments}

I am very much grateful to all participants who have participated in this anthropometric research. I am also thankful to BPKIHS for giving permission to conduct the study.

\section{Conflict of interest: none declared.}

\section{References}

1. Raji JM, Garba SH, Numan Al, Waziri MA, Maina MB. Morphological evaluation of head and face shapes in a North-Eastern Nigerian Population. Aust J Basic \& Appl Sci 2010; 4(8): 3338-3341.

2. Shah GV, Jadhav HR.The Study of cephalic index in students of Gujarat. J Anat Soc India 2004; 53 (1): 25-26.

3. Kolar JC, Salter EM. Craniofacial anthropometry: practical measurement of the head and face for clinical, surgical and research use. Springfield IL: C.C.Thomas, 1997.

4. Joshi BL, Rose LE. Nepal-Caste and ethnicity [Internet]. 1991. URL: http://www.photius.com/countries/nepal/society/nepal_society_cast e_and_ethnicity.html

5. Jahanshahi M, Golalipour MJ, Heidari K. The effect of ethnicity on facial anthropometry in Northern Iran. Singapore Med J 2008; 49(11): 940-943. (PMID: 19037564)

6. Panero J. Human dimension and inferior space. First edition. London: Architectural Press Ltd, 1979

7. Zhuang Z, Bradtmiller B. Head and face anthropometric survey of US respirator users. J Occup Environ Hyg 2005; 2: 567-576. (PMID: 16223715) (doi: 10.1080/15459620500324727)

8. Lili D, Zhaung Z, Guan H, Xing J, Tang X, Wang L, et al. Head-and-face anthropometric survey of Chinese workers. Ann Occup Hyg 2008; 52(8): 773-782. (doi: 10.1093/annhyg/men056) (PMID: 18765398)

9. Garba H, Numan Al, Mishara IG. Craniofacial classification of normal newborns in Maiduguri metropolis, Nigeria. Int J Morphol 2008; 26(2): 407-410. (doi: 10.4067/S0717-95022008000200026)

10. Golalipour MJ. Capacity and brain weight of male newborns in Northern Iran. Neuroembryology and Aging 2005; 3: 146-148.

11. Heidari Z, Mahmoodzadeh sagheb HR, Mohammadi M, Noori Moogehi $\mathrm{SMH}$, Arab A. Cephalic and prosopic indices: comparison in 1-day newborn boys in Zahedan. Tehran Univ Med J 2004, 62(2): 156-165.

12. Heidari Z, Mahmoudzadeh Sagheb HR, Noori Mugahi MH. Morphological evaluation of head and face in 18-25 years old women in southeast of Iran. J Med Sci 2006; 6: 400-404. (doi: 10.3923/jms.2006.400.404)

13. Mibodi IMA, Frahani MR. Study of normal range of anatomical dimensions of one-day old newborn by cephalometry. J Med Council Islamic Republic of Iran 1996; 74: 1-8.

14. Mehrannia. Fifth National Congress of Anatomy.Tehran, Iran, 2001; 34. Persian

15. Ghosh S, Malik SL. Sex differences in body size and shape among Santhals of West Bengal. Anthropol 2007; 9: 143-149.

\section{Authors:}

Sandip Shah - BDS, MS, Assistant professor, Department of Human Anatomy, BP Koirala Institute of Health Sciences, Dharan, Nepal.

Laxman Khanal - BDS, MS, Assistant professor, Department of Human Anatomy, BP Koirala Institute of Health Sciences, Dharan, Nepal.

Sarun Koirala - BDS, MS, Associate Professor, Department of Human Anatomy, BP Koirala Institute of Health Sciences, Dharan, Nepal.

Soumya Chakraborty Bhattacharya - MBBS, MS, Professor of Anatomy, Department of Anatomy, West Bengal University of Health Sciences, Salt Lake City, Kolkata, West Bengal, India. 